\title{
so
}

Reprinted from the Journal of the American Chemical Society, 1992, 114.

Copyright (c) 1992 by the American Chemical Society and reprinted by permission of the copyright owner.

\section{The Surface Chemistry of Vinyl Iodide on Pt(111)}

\section{Z.-M. Liu, X.-L. Zhou, D. A. Buchanan, J. Kiss, and J. M. White*}

Contribution from the Department of Chemistry and Biochemistry, University of Texas at Austin, Austin, Texas 78712. Received July 29, 1991

\begin{abstract}
Regardless of exposure, only submonolayer amounts of vinyl iodide $\left(\mathrm{CH}_{2} \mathrm{CHI}\right)$ decompose, either during adsorption on $\mathrm{Pt}(111)$ at $100 \mathrm{~K}$ or during subsequent heating to $165 \mathrm{~K}$. The remainder desorbs molecularly. The dissociation products are vinyl $\left(\mathrm{CH}_{2} \mathrm{CH}\right)$ fragments, an important $\mathrm{C}_{2}$ intermediate in hydrocarbon catalysis, and atomic iodine. Using the tools of surface science we have explored the formation and subsequent reactions of vinyl species in the presence of unavoidably coadsorbed atomic iodine. While some vinyl exists up to $450 \mathrm{~K}$, there are two important and competitive lower temperature reaction channels which lead to ethylidyne $\left(\mathrm{CCH}_{3}\right)$ and ethylene $\left(\mathrm{CH}_{2} \mathrm{CH}_{2}\right)$. From our results, we conclude that the rate of ethylidyne formation from adsorbed ethylene is controlled by the rate at which the first $\mathrm{C}-\mathrm{H}$ bond in ethylene breaks, and in agreement with Zaera, ${ }^{1,2}$ we find that vinyl is a facile intermediate in the process.
\end{abstract}

\section{Introduction}

Numerous experimental and theoretical studies have dealt with the chemisorption and reactions, particularly to form ethylidyne, of ethylene on $\mathrm{Pt}(111)$. $^{3-5}$ During heating from low temperatures, a strong hydrogen-desorption peak, which accompanies the de-

(1) Zaera, F. J. Am. Chem. Soc. 1982, $111(12), 4240$

(2) Zaera, F. Surf. Sci. 1989, 219, 453.

(3) Lloyd, K. G.; Campion, A.; White, J. M. Catal. Lett. 1989, 2, 105 and references therein.

(4) Carter, E. A.; Koel, B. E. Surf. Sci. 1990, 226, 339 and references therein.

(5) Silvestre, J.; Hoffmann, R. Langmuir 1985, 1(6), 621. composition of di- $\sigma$-bonded ethylene to form ethylidyne, is observed near $300 \mathrm{~K}$. A second strong hydrogen-desorption peak, at 512 $\mathrm{K}$, accompanies the conversion of ethylidyne to a polymonic hydrogen-deficient species. ${ }^{4}$ Although the structures of ethylene and ethylidyne on $\mathrm{Pt}(111)$ have been well established, the mechanism of conversion from ethylene to ethylidyne remains controversial. Several intermediates, such as ethyl $\left(\mathrm{CH}_{2} \mathrm{CH}_{3}\right),{ }^{6}$ vinyl (CHC$\left.\mathrm{H}_{2}\right)$, ${ }^{1,2}$ ethylidene $\left(\mathrm{CHCH}_{3}\right),{ }^{7}$ and vinylidene $\left(\mathrm{CCH}_{2}\right)$, have been

(6) Bent, B. E. Ph.D. Dissertation, University of California-Berkeley, 986.

(7) Ibach, H.; Lehwald, S. J. Vac. Sci. Technol. 1978, 15, 407.

(8) Baro, A. M.; Ibach, H. Vide, Couches Minces, Suppl. 1980, $201,458$. 


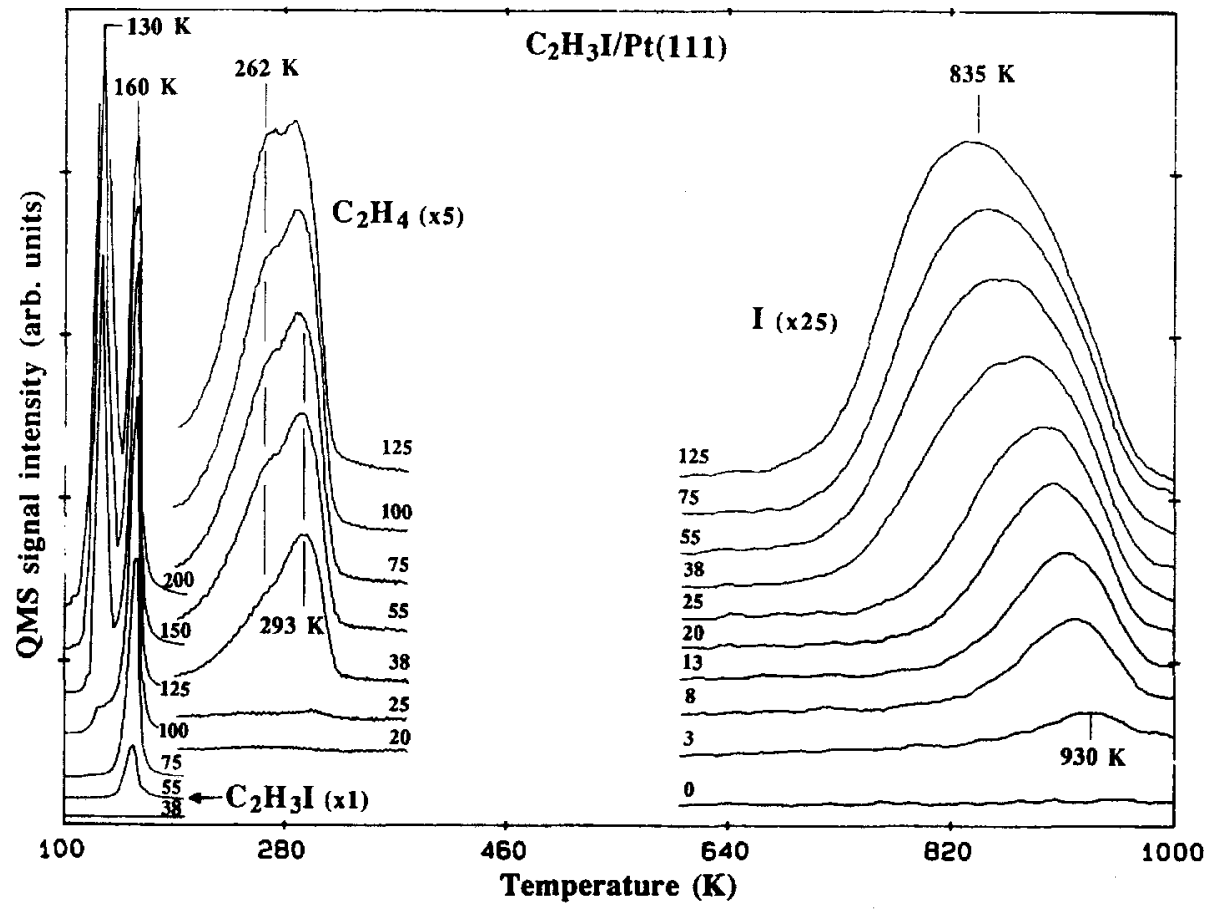

Figure 1. TPD spectra of mass $27\left(\mathrm{C}_{2} \mathrm{H}_{3}{ }^{+}\right), 127\left(\mathrm{I}^{+}\right)$, and $154\left(\mathrm{C}_{2} \mathrm{H}_{3} \mathrm{I}^{+}\right)$for various $\mathrm{C}_{2} \mathrm{H}_{3} \mathrm{I}$ exposures (indicated by the dosing time on each curve). The exposure temperature was $100 \mathrm{~K}$, and the TPD heating rate was $6 \mathrm{~K} / \mathrm{s}$.

proposed. In deuterium-substitution experiments, Zaera ${ }^{1,2}$ proposed that the formation of vinyl fragments, instead of ethylidene, should be favored in the conversion mechanism mentioned above.

In order to confirm that vinyl species play an important role, we studied the adsorption, dissociation, and reactions of vinyl iodide on $\mathrm{Pt}(111)$ using a variety of surface science tools. Because the $\mathrm{C}-\mathrm{I}$ bond is much weaker than the $\mathrm{C}-\mathrm{H}$ bond, we expect that $\mathrm{C}_{2} \mathrm{H}_{3}$ I dissociates to form $\mathrm{CHCH}_{2}$ fragments at lower temperatures than does $\mathrm{C}_{2} \mathrm{H}_{4}$. Indeed, we found that, even at $100 \mathrm{~K}$, vinyl fragments form. They readily convert directly to ethylidyne at temperatures as low as $120 \mathrm{~K}$. Hydrogenation of $\mathrm{CHCH}_{2}$ to ethylene and ethyl is also observed, but only for coverages above a threshold and/or in the presence of coadsorbed atomic hydrogen.

\section{Experimental Section}

The experiments were carried out in two separate ultrahigh-vacuum chambers. One was equipped with temperature-programmed desorption (TPD), temperature-programmed secondary-ion mass spectrometry (TPSIMS), high-resolution electron energy loss spectroscopy (HREELS), and Auger electron spectroscopy (AES) facilities and has been described elsewhere. ${ }^{9}$ The second chamber housed a Kratos Series $800 \mathrm{X}$-ray photoelectron spectrometer (XPS) and TPD equipment; a more detailed description has been given previously. ${ }^{10}$

The $\mathrm{Pt}(111)$ crystal was cleaned by $\mathrm{Ar}$ ion sputtering, oxidation at $900-1000 \mathrm{~K}$ in $5 \times 10^{-8}$ Torr of oxygen to remove carbon, and annealing at $1200 \mathrm{~K}$ for several minutes to remove residual oxygen. The surface cleanliness was checked by AES. Vinyl iodide ( $99 \%$, Pfaltz \& Bauer) was purified by several freeze-pump-thaw cycles under liquid nitrogen. The vinyl iodide was dosed through a 3-mm-diameter tube that terminated approximately $1 \mathrm{~cm}$ from the sample.

TPD and TPSIMS were performed with a temperature ramping rate of 6 or $4.5 \mathrm{~K} / \mathrm{s}$. The temperature was measured with a chromel-alumel thermocouple spot-welded to the back of the sample. An 800-eV Ar ${ }^{+}$ beam and a beam flux of $5-30 \mathrm{nA} / \mathrm{cm}^{2}$ was used for TPSIMS. The dosing temperature was $100 \mathrm{~K}$ unless otherwise noted.

In XPS measurements, a Mg Ka source was used and the analyzer was set for $40-\mathrm{eV}$ pass energy and $0.05-$ or $0.10-\mathrm{eV}$ step size. XPS core level spectra of $\mathrm{I}\left(3 \mathrm{~d}_{5 / 2}\right)$ and $\mathrm{C}(\mathrm{Is})$ were recorded.

HREELS measurements were carried out with a primary beam energy of $6.1 \pm 0.2 \mathrm{eV}$ and a resolution of $10-12 \mathrm{mV}$ full width at half-maximum (FWHM). In the annealing sets described below, the sample was

(9) Mitchell, G. E.; Radloff, P. L.; Greenlief, C. M.; Henderson, M. A.; White, J. M. Surf. Sci. 1987, 183, 403.

(10) Jo, S. J.; Zhu, X.-Y.; Lennon, D.; White, J. M. Surf. Sci. 1991, 241,

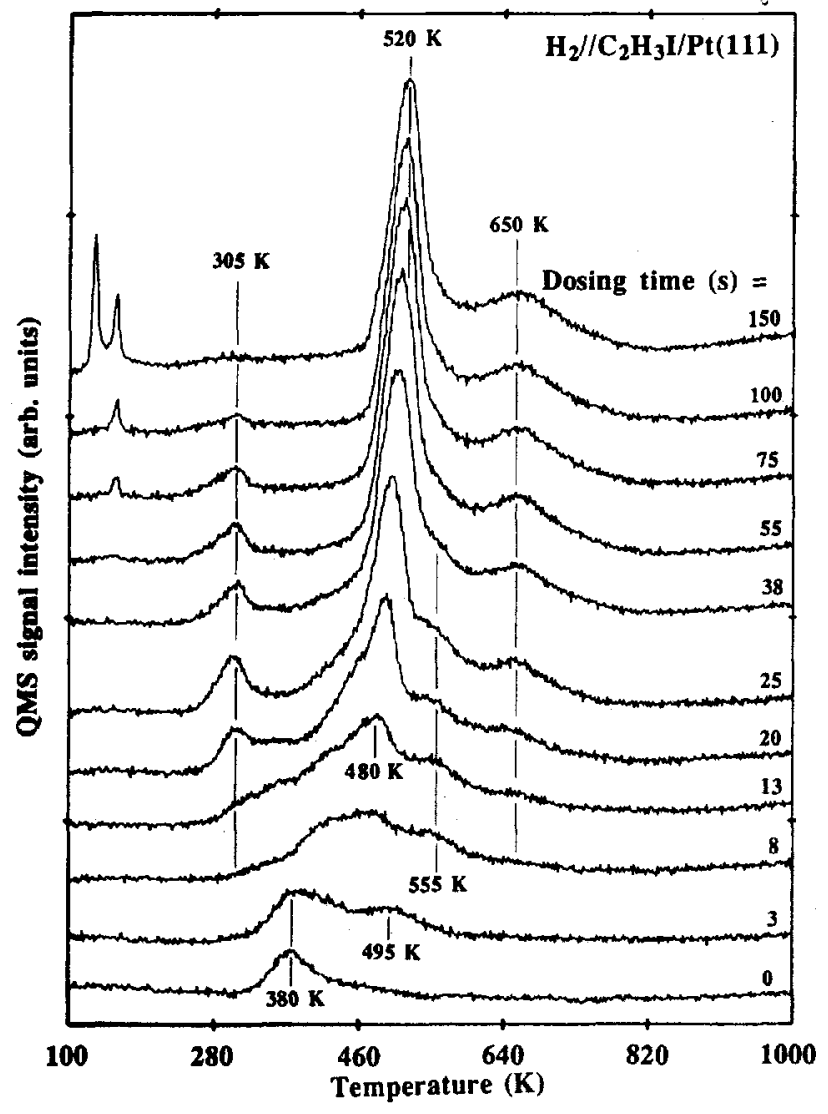

Figure 2. TPD spectra of mass $2\left(\mathrm{H}_{2}^{+}\right)$for various $\mathrm{C}_{2} \mathrm{H}_{3} \mathrm{I}$ exposures (indicated by the dosing time on each curve). The exposure temperature was $100 \mathrm{~K}$, and the heating rate was $6 \mathrm{~K} / \mathrm{s}$.

flashed to the desired temperature and cooled to $105 \mathrm{~K}$ before the spectra were taken.

\section{Results}

3.1. $\mathrm{C}_{2} \mathrm{H}_{3} \mathrm{I} / \mathrm{Pt}(111)$. 3.1.1. TPD and AES. Detailed TPD spectra are presented in Figures 1 and 2; peak areas and the AES $\mathrm{C} / \mathrm{Pt}$ ratio as a function of dosing time are summarized in Figure 3. Briefly, TPD and AES demonstrate the following. The only 


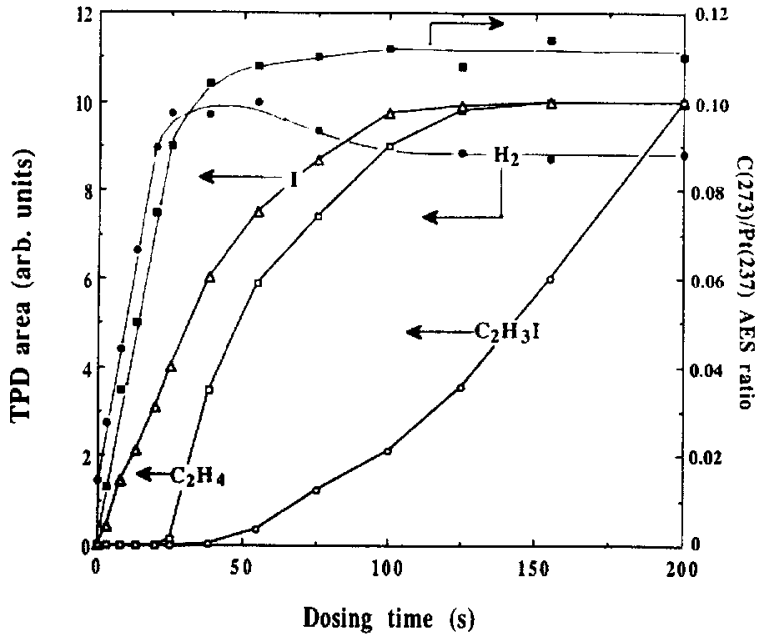

Figure 3. Exposure time dependence of TPD areas, from Figures 1 and 2, for $\mathrm{H}_{2}, \mathrm{C}_{2} \mathrm{H}_{4}$, I, and $\mathrm{C}_{2} \mathrm{H}_{3} \mathrm{I}$, and of the $\mathrm{C}(273) / \mathrm{Pt}(237) \mathrm{AES}$ ratio.

products desorbing up to $1000 \mathrm{~K}$ are parent $\mathrm{C}_{2} \mathrm{H}_{3} \mathrm{I}, \mathrm{H}_{2}, \mathrm{C}_{2} \mathrm{H}_{4}$, and atomic I. After TPD, there is a significant C AES signal.

Figure 1 shows TPD spectra of $\mathrm{C}_{2} \mathrm{H}_{3} \mathrm{I}, \mathrm{C}_{2} \mathrm{H}_{4}$, and $\mathrm{I}$ as a function of dosing time (designated on each curve). Indicating complete C-I dissociation, no molecular $\mathrm{C}_{2} \mathrm{H}_{3} \mathrm{I}$ desorbs for doses shorter than $38 \mathrm{~s}$ (Figure 3). For longer doses, a parent peak appears at $160 \mathrm{~K}$ and, with no shift, intensifies to saturation (near 110 s). An unsaturable peak then appears at $130 \mathrm{~K}$. We assign the $130 \mathrm{~K}$ peak to the physisorbed multilayers and the $160 \mathrm{~K}$ peak to the chemisorbed monolayer $\mathrm{C}_{2} \mathrm{H}_{3} \mathrm{I}$. For doses shorter than 38 $\mathrm{s}$, the atomic I TPD area increases linearly with time, and for doses longer than $125 \mathrm{~s}$, the parent TPD area increases linearly. Both indicate a constant sticking coefficient. This fact is used in the quantitative coverage estimates that follow.

Surface I, derived from C-I dissociation, desorbs atomically above $700 \mathrm{~K}$. Its peak temperature shifts downward with increasing dose (from $930 \mathrm{~K}$ for $3 \mathrm{~s}$ to $835 \mathrm{~K}$ for $125 \mathrm{~s}$ ), and the TPD area saturates (Figure 3 ) for doses exceeding $100 \mathrm{~s} . \mathrm{I}^{+}$ signals are also found at 130 and $160 \mathrm{~K}$ (not shown), but they are the quadrupole mass spectrometer (QMS) ionizer cracking fragments of parent $\mathrm{C}_{2} \mathrm{H}_{3} \mathrm{I}$. In agreement with Zaera, ${ }^{2}$ who studied $\mathrm{C}_{2} \mathrm{H}_{5} \mathrm{I}$ on $\mathrm{Pt}(111)$, we find that $\mathrm{I}$ is lost from the surface around $800 \mathrm{~K}$. Our interpretation, atomic desorption, is different. On the basis of XPS signal loss but the lack of a QMS signal for I, Zerra ${ }^{2}$ suggested, we believe erroneously, that diffusion into Pt might be important.

Ethylene $\left(\mathrm{C}_{2} \mathrm{H}_{4}\right)$ desorption occurs, but only for doses longer than $25 \mathrm{~s}$. Like I and the chemisorbed parent, its peak area (Figure 3) saturates at $110 \mathrm{~s}$. The desorption begins at $\sim 200$ $\mathrm{K}$, nearly $50 \mathrm{~K}$ lower than for directly dosed ethylene, ${ }^{11}$ and two peaks are apparent with increasing exposure (293 and $262 \mathrm{~K}$ ). The desorption of molecular ethylene implies a surface reaction (most likely the hydrogenation of vinyl species), described in detail below. The absence of ethylene TPD for low doses indicates competing reaction channels and important coverage dependences (site blocking and stabilization of key intermediates).

Figure 2 shows TPD spectra of $\mathrm{H}_{2}(m / e=2)$. We use the nomenclature $Z / / Y / X / P t(111)$ to indicate TPD of $Z$ from $P t-$ (111) dosed first with $X$ and then with $Y$. Without dosing $\mathrm{C}_{2} \mathrm{H}_{3} \mathrm{I}$, there is a small peak at $380 \mathrm{~K}$ due to the adsorption of background $\mathrm{H}_{2}$. For low exposures ( 3 and $8 \mathrm{~s}$ ), TPD shows multiple, coverage-dependent $\mathrm{H}_{2}$ peaks above 300 and below $600 \mathrm{~K}$. These are ascribed to two sources: background $\mathrm{H}_{2}$ and decomposition of $\mathrm{C}_{2} \mathrm{H}_{3} \mathrm{I}$. For intermediate exposures (13-25 s), there are four $\mathrm{H}_{2}$ peaks; three of them, 305,555 , and $650 \mathrm{~K}$, are independent of $\mathrm{C}_{2} \mathrm{H}_{3} \mathrm{I}$ exposure, while the fourth peak shifts, for 13-25 s, from 480 to $510 \mathrm{~K}$. For higher exposures, the peak positions do not change, the $555 \mathrm{~K}$ peak is overwhelmed by the $520 \mathrm{~K}$ peak, and

(11) Creighton, J. R.; White, J. M. Surf. Sci. 1983, 129, 327. the $305 \mathrm{~K}$ peak rises and then decays. The low-temperature signals for exposures greater than $55 \mathrm{~s}$ are cracking fragments of parent vinyl iodide desorption.

The four higher temperature peaks are reminiscent of $\mathrm{H}_{2}$ desorption following ethylene adsorption on $\mathrm{Pt}(111),{ }^{11}$ a particularly relevant case since ethylene desorbs here (Figure 1). Following the ethylene case, these peaks can be assigned as follows: ${ }^{11}$ (1) the $305 \mathrm{~K}$ peak to atomic $\mathrm{H}$ recombination occurring as the result of $\mathrm{C}-\mathrm{H}$ bond cleavage in di- $\sigma$-bonded ethylene, the latter formed at slightly lower temperatures by hydrogenation of vinyl; (2) the $520 \mathrm{~K}$ peak to one or more $\mathrm{C}-\mathrm{H}$ bond cleavages in ethylidyne; and (3) the $650 \mathrm{~K}$ peak to $\mathrm{C}-\mathrm{H}$ bond cleavage in the remaining surface $\mathrm{C}_{x} \mathrm{H}_{y}$ polymer. Referring to Figure 3 , the $\mathrm{H}_{2}$ TPD area increases linearly up to $25 \mathrm{~s}$. Linearity is expected since $\mathrm{H}_{2}$ is the only $\mathrm{H}$-containing TPD product and, by extrapolation, the sticking coefficient is constant. After a plateau from 25 to 55 $s$, the $\mathrm{H}_{2}$ TPD area decreases slightly and becomes constant for doses longer than $110 \mathrm{~s}$.

In addition to TPD areas, Figure 3 shows the $\mathrm{C}(273) / \mathrm{Pt}(237)$ AES ratio measured after TPD to $1000 \mathrm{~K}$. It increases sharply to saturation at $110 \mathrm{~s}$, consistent with the behavior of $\mathrm{C}_{2} \mathrm{H}_{3} \mathrm{I}, \mathrm{H}_{2}$, $\mathrm{C}_{2} \mathrm{H}_{4}$, and I TPD areas. It is evident that $\mathrm{C}-\mathrm{I}$ dissociation ceases upon completion of the first monolayer and perhaps even before. For the chemisorbed layer, however, both molecular desorption and dissociation occur, with dissociation dominating at low coverages.

With reasonable assumptions, we can estimate some relevant coverages. Assuming, for dissociative $\mathrm{H}_{2}$ adsorption on $\mathrm{Pt}(111)$ at $100 \mathrm{~K}$, that saturation is reached when the $\mathrm{H} / \mathrm{Pt}$ surface atom ratio reaches unity, ${ }^{12}$ we can calibrate $\mathrm{H}_{2}$ desorption peak areas. On the basis of the measured saturation $\mathrm{H}_{2}$ TPD area, we calculate that the initial linear increase in $\mathrm{H}_{2}$ TPD area (Figure 3) implies a $\mathrm{C}_{2} \mathrm{H}_{3} \mathrm{I}$ adsorption rate of 0.004 adsorbates, where no ethylene desorbs, per surface $\mathrm{Pt}$ atom per second $(0.004 \mathrm{ML} / \mathrm{s}$ (monolayer/second)). Because the completion of the first layer $\mathrm{C}_{2} \mathrm{H}_{3} \mathrm{I}$ requires $110 \mathrm{~s}$, the saturation first layer coverage, were there no dissociation, would be $0.44 \mathrm{ML}$ assuming, consistent with the multilayer growth rate, a coverage-independent sticking coefficient. In fact, there is dissociation, and of the $0.44 \mathrm{ML}$ that sticks, we conclude that $0.14 \mathrm{ML}(\sim 30 \%)$ desorbs molecularly and 0.30 ML $(\sim 70 \%)$ dissociates. We can go further using the low-coverage $\mathrm{H}_{2}$ TPD data (complete dissociation) to calibrate the C/Pt AES data. Of the $0.30 \mathrm{ML}$ that dissociates, only $0.13 \mathrm{ML}$ decomposes completely to surface carbon. Thus, for a saturated chemisorbed monolayer of $\mathrm{C}_{2} \mathrm{H}_{3} \mathrm{I}$ on $\mathrm{Pt}(111)$ at $100 \mathrm{~K}(0.44 \mathrm{ML})$, the $\mathrm{C}_{2} \mathrm{H}_{4}$ yield is $0.17 \mathrm{ML}$ (40\%). For these coverage conditions, the $\mathrm{H}_{2}$ TPD area indicates an ethylidyne coverage of $0.10 \mathrm{ML}$.

To establish more clearly the connections between ethylene and vinyl iodide surface chemistry, we show in Figure 4 dihydrogen TPD spectra for saturation monolayer doses of $\mathrm{C}_{2} \mathrm{H}_{3} \mathrm{I}, \mathrm{C}_{2} \mathrm{H}_{4}$, and $\mathrm{C}_{2} \mathrm{D}_{4}$. In excellent agreement with earlier work, $11,13,14$ there are discernible peaks for $\mathrm{C}_{2} \mathrm{H}_{4}$ at 302,502 , and $645 \mathrm{~K}$ and shoulders below and above $645 \mathrm{~K}$. A small isotope effect, but nothing more, distinguishes the $C_{2} D_{4}$ case. For ethylene, it is well established that the lowest dihydrogen TPD peak is reaction-limited $\mathrm{C}-\mathrm{H}$ bond cleavage in di- $\sigma$-bonded ethylene, a dissociation accompanied by ethylidyne formation. " For $\mathrm{C}_{2} \mathrm{H}_{3} \mathrm{I}$ in Figure 4, this peak is absent, indicating that the reaction channel converting di- $\sigma$-bonded ethylene to ethylidyne is not operative. This channel ( $305 \mathrm{~K})$ rises and falls as a function of vinyl iodide exposure (Figure 2).

The higher temperature regions for all three cases are strikingly similar, supporting the notion that ethylidyne formation and decomposition contribute to the surface chemistry of vinyl iodide. There are, however, reproducible differences; for vinyl iodide, the lower temperature peak is shifted to higher temperatures ( 502 to $520 \mathrm{~K}$ ) and the shoulders observed for both ethylenes are absent. To pursue this further, we prepared deuterated ethylidyne, $\mathrm{CCD}_{3}$, by dosing a saturation amount of $\mathrm{C}_{2} \mathrm{D}_{4}$ at $100 \mathrm{~K}$ and heating it

(12) Weinberg, W. H. Surv. Prog. Chem. 1983, 10, 1

(13) Steininger, H.; Ibach, H.; Lehwald, S. Surf, Sci. 1982, 117, 341. (14) Salmeron, M.; Somorjai, G. A. J. Phys. Chem. 1982, 86, 341. 


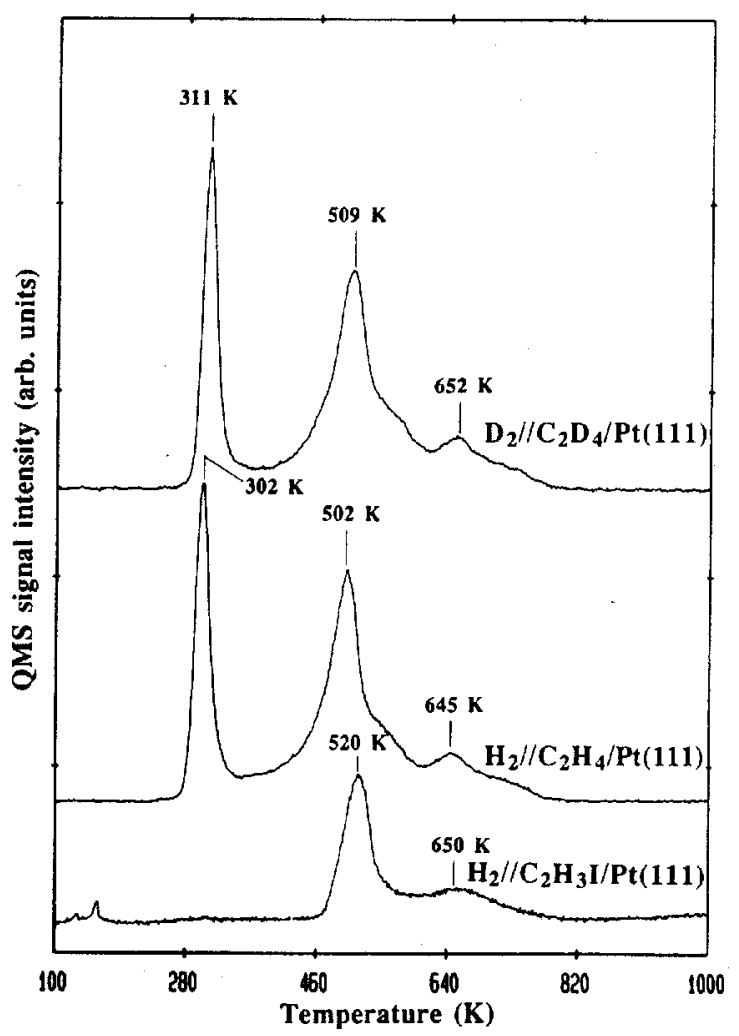

Figure 4. TPD spectra of dihydrogen for saturated monolayer $\mathrm{C}_{2} \mathrm{H}_{3} \mathrm{I}$, $\mathrm{C}_{2} \mathrm{H}_{4}$, and $\mathrm{C}_{2} \mathrm{D}_{4}$. The exposure temperature was $100 \mathrm{~K}$, and the heating rate was $6 \mathrm{~K} / \mathrm{s}$.

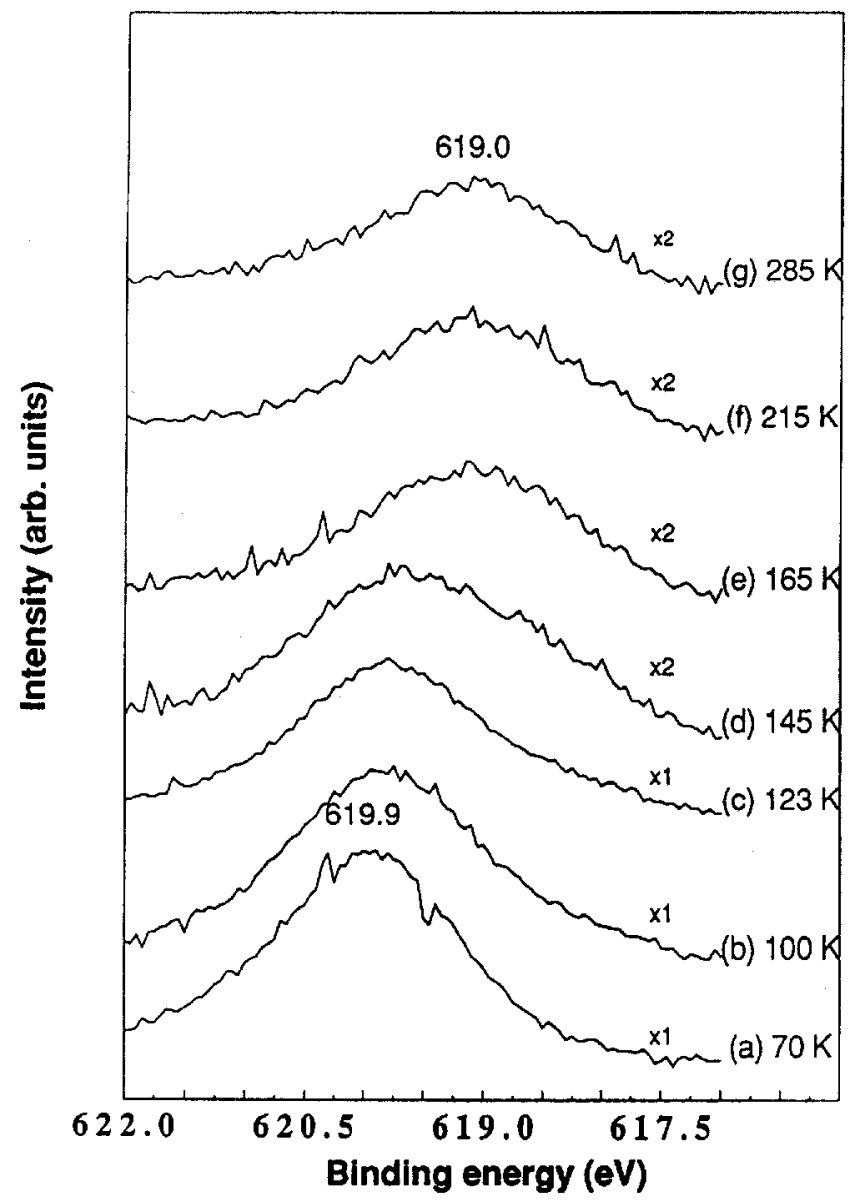

Figure 5. I(3d) XPS core level spectra for a multilayer dose of $\mathrm{C}_{2} \mathrm{H}_{3} \mathrm{I}$ at $70 \mathrm{~K}$ (a), then warmed briefly to (b) $100 \mathrm{~K}$, (c) $123 \mathrm{~K}$, (d) $145 \mathrm{~K}$, (e) $165 \mathrm{~K}$, (f) $215 \mathrm{~K}$, and (g) $285 \mathrm{~K}$. All XPS spectra were taken after recooling to below $100 \mathrm{~K}$.
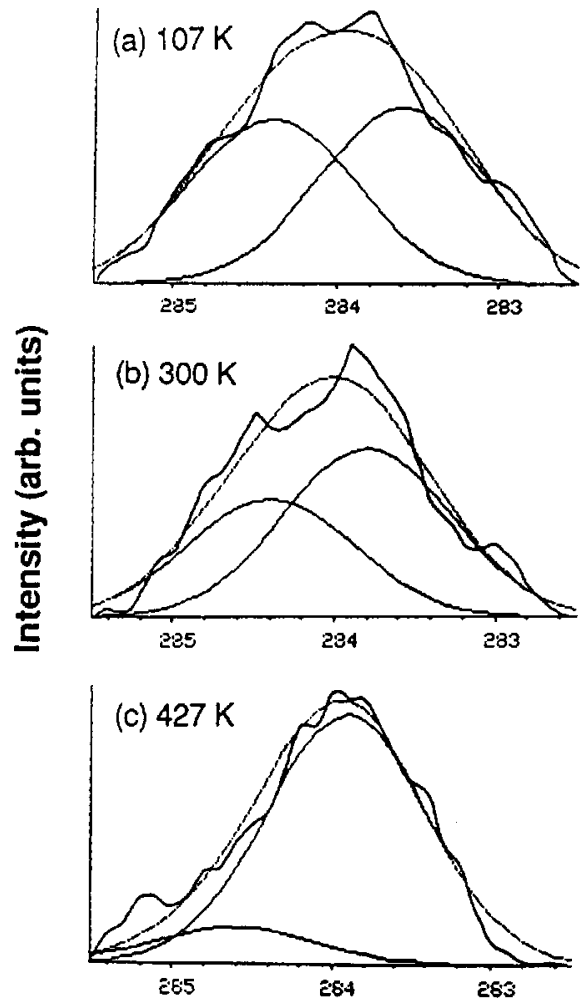

Binding energy $(\mathrm{eV})$

Figure 6. $\mathrm{C}(1 \mathrm{~s})$ XPS core level spectra for a multilayer dose of $\mathrm{C}_{2} \mathrm{H}_{3} \mathrm{I}$ on $\mathrm{Pt}(111$ ) at $70 \mathrm{~K}$, then warmed briefly to (a) $107 \mathrm{~K}$, (b) $300 \mathrm{~K}$, and (c) $427 \mathrm{~K}$. All spectra were taken after recooling to below $100 \mathrm{~K}$. The broad, somewhat noisy spectra are the experimental data, while the smooth curves are synthesized fits using Gaussian profiles.

to $375 \mathrm{~K}$. After recooling to $100 \mathrm{~K}$, we added $0.44 \mathrm{ML}$ of $\mathrm{C}_{2} \mathrm{H}_{3} \mathrm{I}$. During subsequent TPD, there was significant dissociation, and the resulting profile mimicked the lower curve of Figure 4, i.e., shifted TPD with no shoulders. This experiment indicates a discernible role for I, i.e., stabilizing ethylidyne, thereby shifting its reaction-limited decomposition to slightly higher temperatures, and causing TPD peaks to sharpen.

3.1.2. XPS. X-ray photoelectron spectroscopy, undertaken to provide direct evidence for changes in surface atomic composition and chemical environment, is summarized in Figures 5 and 6. I(3d) for a multilayer of $\mathrm{C}_{2} \mathrm{H}_{3} \mathrm{I}$ on $\mathrm{Pt}(111)$, dosed at $70 \mathrm{~K}$, has a peak at $619.9 \mathrm{eV}$. While heating to $100 \mathrm{~K}$ desorbs nothing, the I(3d) peak broadens slightly toward lower binding energy (BE), signaling some $\mathrm{C}-\mathrm{I}$ bond dissociation. With further heating, the peak becomes less intense, broadens further, and shifts to 619.0 $\mathrm{eV}$ at $165 \mathrm{~K}$. The intensity loss (note the scale change at 145 $\mathrm{K}$ ) is due to the desorption of $\mathrm{C}_{2} \mathrm{H}_{3} \mathrm{I}$ multilayers at $130 \mathrm{~K}$. The shift to lower BE is attributed to thermally activated C-I dissociation. These changes cease above $165 \mathrm{~K}$, indicating that parent molecules which undergo dissociation do so below $165 \mathrm{~K}$. Taking the area of curve $d(145 \mathrm{~K}$ ) as one monolayer (see Figure 1), we calculate, on the basis of the area at $215 \mathrm{~K}$, that $72 \%$ of $\mathrm{C}_{2} \mathrm{H}_{3} \mathrm{I}$ in the first monolayer is dissociated. This compares favorably with the estimate (70\%) from TPD results (see above).

Figure 6 shows C(1s) spectra for a multilayer dosed on $\mathrm{Pt}(111)$ at $70 \mathrm{~K}$ and then heated to the indicated temperatures. The thick, somewhat noisy curves are the experimental data; the smooth curves are synthesized fits using Gaussian profiles with widths based on standard $\mathrm{C}(1 \mathrm{~s})$ spectra. ${ }^{15,16}$ At $107 \mathrm{~K}$, as expected, the width requires two peaks (283.6 and $284.4 \mathrm{eV}$ ) of nearly equal intensity in the fit. These are assigned to the two $C(1 s)$ chemical

(15) Akhter, S.; Allan, K.; Buchanan, D.; Cook, J. A.; Campion, A.; White, J. M. Appl. Surf. Sci. 1988-1989, 35, 241.

(16) Freyer, N.; Pirug, G.; Bonzel, H. P. Surf. Sci. 1983, 126, 487. 


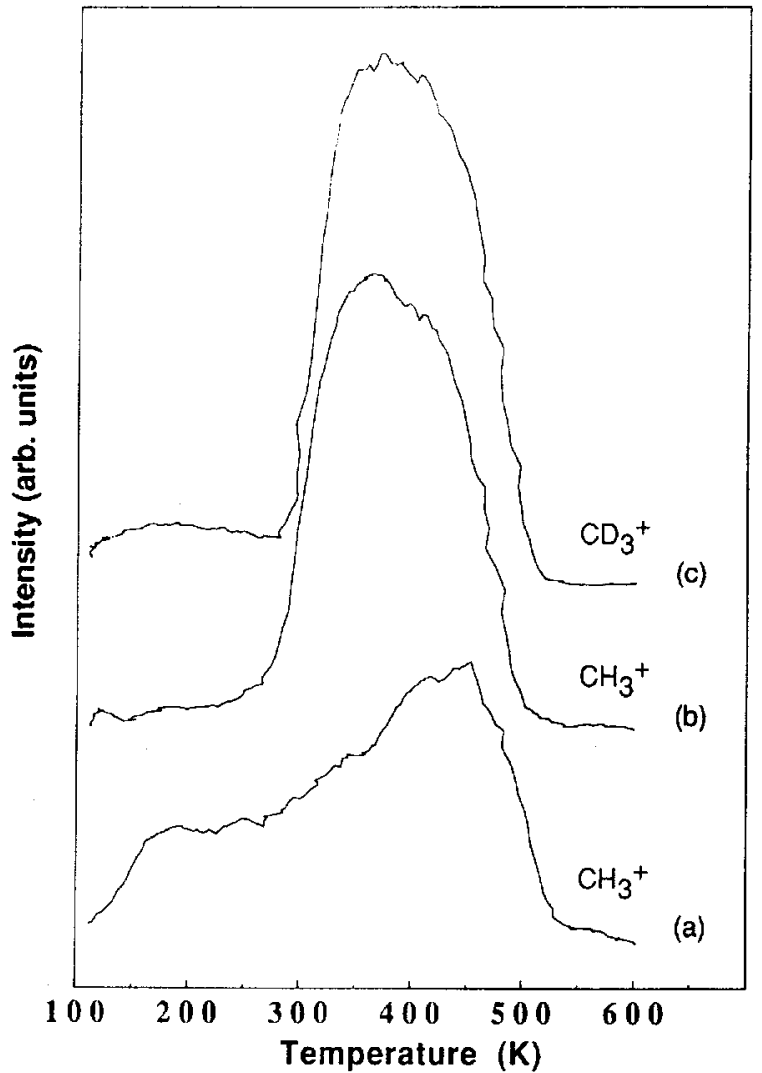

Figure 7. TPSIMS spectra of methyl ions from surfaces saturated with monolayers of $\mathrm{C}_{2} \mathrm{H}_{3} \mathrm{I}(\mathrm{a}), \mathrm{C}_{2} \mathrm{H}_{4}$ (b), and $\mathrm{C}_{2} \mathrm{D}_{4}$ (c). The dosing temperature was $120 \mathrm{~K}$, and the heating rate was $6 \mathrm{~K} / \mathrm{s}$.

environments in adsorbed molecular $\mathrm{C}_{2} \mathrm{H}_{3} \mathrm{I}$, with the higher $\mathrm{BE}$ associated with the I environment. They compare very favorably with results for undissociated vinyl chloride on $\mathrm{Pt}(111)$ (283.4 and $284.6 \mathrm{eV}$ ). ${ }^{16}$ Some dissociation can account for the slightly more intense lower BE peak. At $300 \mathrm{~K}$, where a significant amount of ethylidyne forms, the lower BE region (283.8 eV) intensifies, its ratio to the higher BE peak becoming 1.5. This continues to $427 \mathrm{~K}$, where the ratio is 10 . These BEs cannot be unambiguously assigned to a single species, but, considering the TPD and TPSIMS (see TPSIMS below) results, there is a good correlation between the intensity of the higher BE peak and vinyl concentration. Vinyl is presumably surrounded by atomic iodine and, thus, shifted to a higher BE $(284.4 \mathrm{eV})$ than might otherwise be expected.

3.1.3. TPSIMS. Previous work ${ }^{11}$ shows that the $\mathrm{CH}_{3}{ }^{+}$ TPSIMS signal $(m / e=15)$ can be used to monitor the surface concentration of ethylidyne. Figure 7 summarizes methyl ion signals after dosing $\mathrm{C}_{2} \mathrm{H}_{3} \mathrm{I}, \mathrm{C}_{2} \mathrm{H}_{4}$, and $\mathrm{C}_{2} \mathrm{D}_{4}$; the analogous TPD spectra are shown in Figure 4. For $\mathrm{C}_{2} \mathrm{H}_{4}$ and $\mathrm{C}_{2} \mathrm{D}_{4}$, the $\mathrm{CH}_{3}{ }^{+}$ and $\mathrm{CD}_{3}{ }^{+}$signals begin to increase (ethylidyne formation) above $250 \mathrm{~K}$ and decrease (ethylidyne decomposition) above $400 \mathrm{~K}$, in agreement with the earlier work. ${ }^{11}$ There is a small isotope effect that favors the formation and decomposition of $\mathrm{CCH}_{3}$, consistent with the TPD results. For $\mathrm{C}_{2} \mathrm{H}_{3} \mathrm{I}$, however, the $\mathrm{CH}_{3}{ }^{+}$signal begins to increase at temperatures as low as $120 \mathrm{~K}$. After a plateau from 200 to $300 \mathrm{~K}$, it increases again until it starts to decay above 450 K. In none of the three cases is there a $\mathrm{CH}_{3}{ }^{+}$signal above 550 K. The $\mathrm{CH}_{3}^{+}$signal from $\mathrm{C}_{2} \mathrm{H}_{3} \mathrm{I}$ is of particular interest; its high-temperature behavior tracks the decomposition of ethylidyne, just as it does for the ethylenes. We take the low-temperature growth as evidence for facile vinyl conversion to ethylidyne without intervention of hydrogenation to ethylene. The increase between 300 and $450 \mathrm{~K}$ is taken to reflect ethylidyne formation from vinyl, stabilized in the presence of high coverages of coadsorbed species (see HREELS below).

3.1.4. HREELS. The evidence shown above points to the dissociation of vinyl iodide and to the formation of at least three
Table I. Assignments for Vinyl Iodide and Vinyl

\begin{tabular}{lcccc}
\hline & $\mathrm{C}_{2} \mathrm{H}_{3} \mathbf{I}^{a}$ & $\begin{array}{c}\mathrm{C}_{2} \mathrm{H}_{3} / \\
\mathrm{Ni}(100)^{b}\end{array}$ & $\begin{array}{c}\mathrm{C}_{2} \mathrm{H}_{3} \mathrm{l} / \\
\mathrm{Pt}(111)^{c}\end{array}$ & $\begin{array}{c}\mathrm{C}_{2} \mathrm{H}_{3} / \\
\mathrm{Pt}(111)^{c}\end{array}$ \\
\hline$\nu-\mathrm{XC}$ & 535 & & 555 & \\
$\rho_{w}-\mathrm{CH}_{2}$ & 990 & 915 & 955 & 955 \\
$\rho_{w}-\mathrm{CH}$ & 946 & 760 & $\mathrm{nr}^{d}$ & 690 \\
$\rho_{\mathrm{t}}-\mathrm{CH}_{2}$ & & & & \\
$\rho_{\mathrm{r}}-\mathrm{CH}_{2}$ & 909 & 1160 & $\mathrm{nr}$ & $\mathrm{nr}$ \\
$\delta-\mathrm{CH}^{2}$ & 1229 & 1280 & 1255 & 1255 \\
$\delta-\mathrm{CH}_{2}(\mathrm{~s})$ & 1376 & 1405 & 1380 & 1380 \\
$\nu-\mathrm{C}=\mathrm{C}$ & 1593 & 1555 & 1565 & 1600 \\
$\nu-\mathrm{CH}$ & 3060 & 2920 & 3070 & 2920 \\
$\nu-\mathrm{CH}_{2}(\mathrm{~s})$ & 3000 & 2920 & $\mathrm{nr}$ & 2920 \\
$\nu-\mathrm{CH}_{2}$ (as) & 3110 & 3090 & 3070 & $\mathrm{nr}$ \\
\hline
\end{tabular}

${ }^{a}$ Reference $28 .{ }^{b}$ Reference 17. ${ }^{c}$ This work. ${ }^{d}$ Not resolved.

Table II. Assignments for Di- $\sigma$-Bonded Ethylene

\begin{tabular}{lccl} 
& $\begin{array}{c}\mathrm{C}_{2} \mathrm{H}_{4} / \\
\mathrm{Pt}(111)^{a}\end{array}$ & $\begin{array}{c}\mathrm{C}_{2} \mathrm{H}_{4} / \mathrm{Cl} / \\
\mathrm{Pt}(111)^{b}\end{array}$ & $\begin{array}{l}\mathrm{C}_{2} \mathrm{H}_{4} / \mathrm{I} / \\
\mathrm{Pt}(111)^{c}\end{array}$ \\
\hline$\nu-\mathrm{PtC}$ & 470 & 457 & 470 \\
$\rho_{w}-\mathrm{CH}_{2}$ & 980 & 985 & $\mathrm{nr}^{d}$ \\
$\nu-\mathrm{CC}$ & 1050 & 1055 & $\mathrm{nr}$ \\
$\delta-\mathrm{CH}_{2}$ (s) & 1430 & 1433 & 1410 \\
$\nu-\mathrm{CH}_{2}$ (s) & 2920 & 2973 & 2970 \\
$\nu-\mathrm{CH}_{2}$ (as) & 3000 & $\mathrm{nr}$ & $\mathrm{nr}$ \\
\hline
\end{tabular}

${ }^{a}$ Reference $13 .{ }^{b}$ Reference 3. ${ }^{c}$ This work. ${ }^{d}$ Not resolved.

Table III. Assignments for Ethylidyne

\begin{tabular}{lccc}
\hline & $\begin{array}{c}\mathrm{CCH}_{3} / \\
\mathrm{Pt}(111)^{a}\end{array}$ & $\begin{array}{c}\mathrm{CCH}_{3} / \mathrm{Cl} / \\
\mathrm{Pt}(111)^{b}\end{array}$ & $\begin{array}{l}\mathrm{CCH}_{3} / \mathrm{I} / \\
\mathrm{Pt}(111)^{c}\end{array}$ \\
\hline $\boldsymbol{\nu}-\mathrm{PtC}$ & 430 & 433 & 440 \\
$\rho_{\rho^{-}}-\mathrm{CH}_{3}$ & 980 & 920 & $\mathrm{nr}^{d}$ \\
$\nu$ & 1130 & 1125 & 1125 \\
$\delta-\mathrm{CC}_{3}$ & 1350 & 1352 & 1360 \\
$\nu-\mathrm{CH}_{3}$ (s) & 2890 & $\mathrm{nr}$ & $\mathrm{nr}$ \\
$\nu-\mathrm{CH}_{3}$ (as) & 2950 & 2970 & 2940 \\
\hline
\end{tabular}

${ }^{a}$ Reference $13,{ }^{b}$ Reference 3. ${ }^{c}$ This work. ${ }^{d}$ Not resolved.

surface species, vinyl $\left(\mathrm{CHCH}_{2}\right)$, ethylene $\left(\mathrm{C}_{2} \mathrm{H}_{4}\right)$, and ethylidyne $\left(\mathrm{CCH}_{3}\right)$. The application of HREELS provides deeper insight into the nature of these surface processes.

Figure 8 shows HREELS spectra as a function of $\mathrm{C}_{2} \mathrm{H}_{3} \mathrm{I}$ exposure on $\mathrm{Pt}(111)$ at $105 \mathrm{~K}$ (exposures in dosing time are indicated on each curve). The vibrational assignments for vinyl iodide and vinyl are given in Table I. For a 25-s dose, the observed losses at $690,955,1380,1600$, and $2920 \mathrm{~cm}^{-1}$ are characteristic of surface vinyl species. ${ }^{17}$ The absence of the C-I stretch $\left(555 \mathrm{~cm}^{-1}\right)$ indicates that all the $\mathrm{C}-\mathrm{I}$ bonds dissociate at $105 \mathrm{~K}$, supporting the XPS results. The shoulder at $1125 \mathrm{~cm}^{-1}$ may reflect some ethylidyne, even at this temperature. For a 50-s dose, both the $\mathrm{C}-\mathrm{I}$ stretching mode at $555 \mathrm{~cm}^{-1}$ and a $\mathrm{C}-\mathrm{H}$ shoulder at 3070 $\mathrm{cm}^{-1}$ appear, substantiating the presence of molecular $\mathrm{C}_{2} \mathrm{H}_{3} \mathrm{I}$. For doses above $100 \mathrm{~s}$, there are additional losses at $1255 \mathrm{~cm}^{-1}(\mathrm{CH}$ rocking) and $1910 \mathrm{~cm}^{-1}$ (overtone of $955 \mathrm{~cm}^{-1}$ ). The peak shifts (upward for $2920 \mathrm{~cm}^{-1}$ and downward for $1600 \mathrm{~cm}^{-1}$ ) are consistent with the dominance of molecular vinyl iodide, rather than dissociated vinyl, at high coverages.

Figure 9 shows HREELS spectra as a function of annealing temperature for a multilayer dose of $\mathrm{C}_{2} \mathrm{H}_{3} \mathrm{I}$ on $\mathrm{Pt}(111)$ at 105 $\mathbf{K}$ (the annealing temperatures are indicated on each curve, and spectra were taken after recooling). The vibrational assignments for ethylene and ethylidyne are given in Tables II and III, respectively. After the surface is heated to $145 \mathrm{~K}$ (not shown), all the features associated with molecular $\mathrm{C}_{2} \mathrm{H}_{3} \mathrm{I}$ decrease, reflecting multilayer desorption. The signal at $555 \mathrm{~cm}^{-1}$ (C-I stretch) indicates the presence of intact chemisorbed parent molecules. The peak at $3070 \mathrm{~cm}^{-1}$ shifts to $3000 \mathrm{~cm}^{-1}$ and becomes broader, suggesting the coexistence of $\mathrm{CHCH}_{2}$ and $\mathrm{C}_{2} \mathrm{H}_{3} \mathrm{I}$. After annealing to $180 \mathrm{~K}$, the $555-\mathrm{cm}^{-1}$ loss disappears, indicating the absence

(17) Zaera, F.; Hall, R. B. Surf. Sci. 1987, 180, 1. 


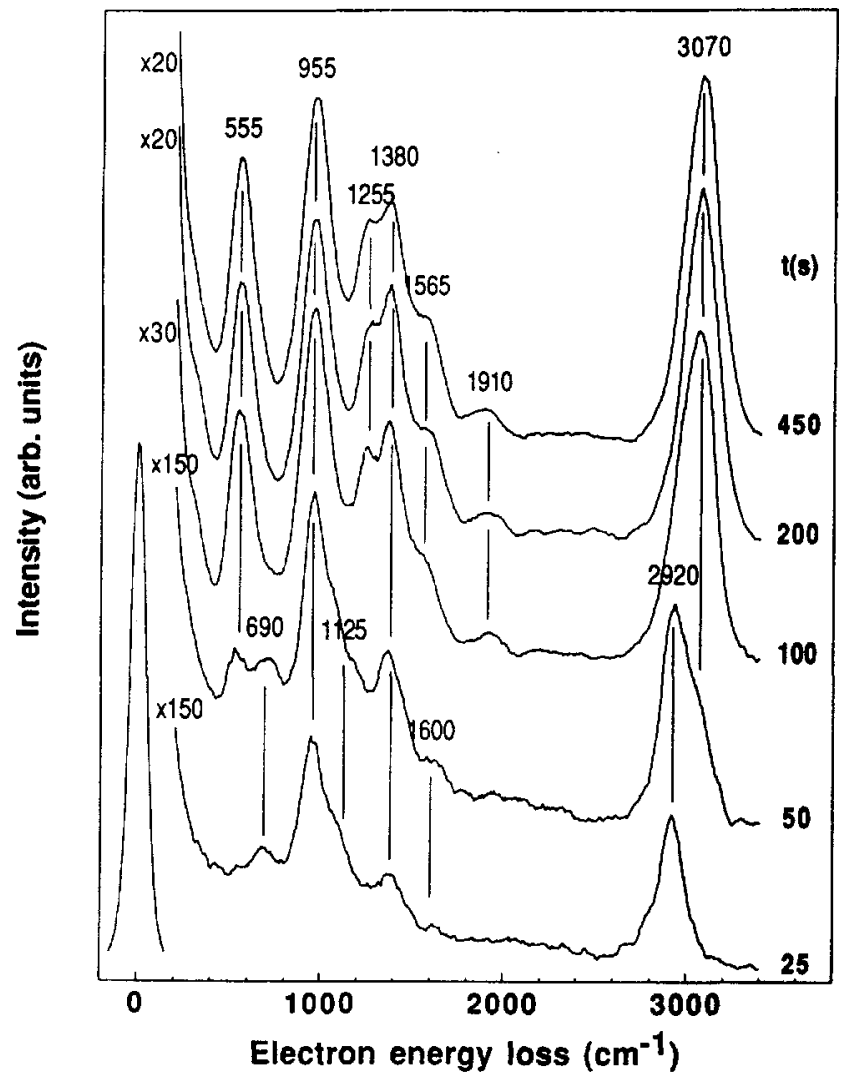

Figure 8. HREELS spectra as a function of $\mathrm{C}_{2} \mathrm{H}_{3} \mathrm{I}$ exposure (exposures in dosing time are indicated on each curve) on Pt(111) at $105 \mathrm{~K}$.

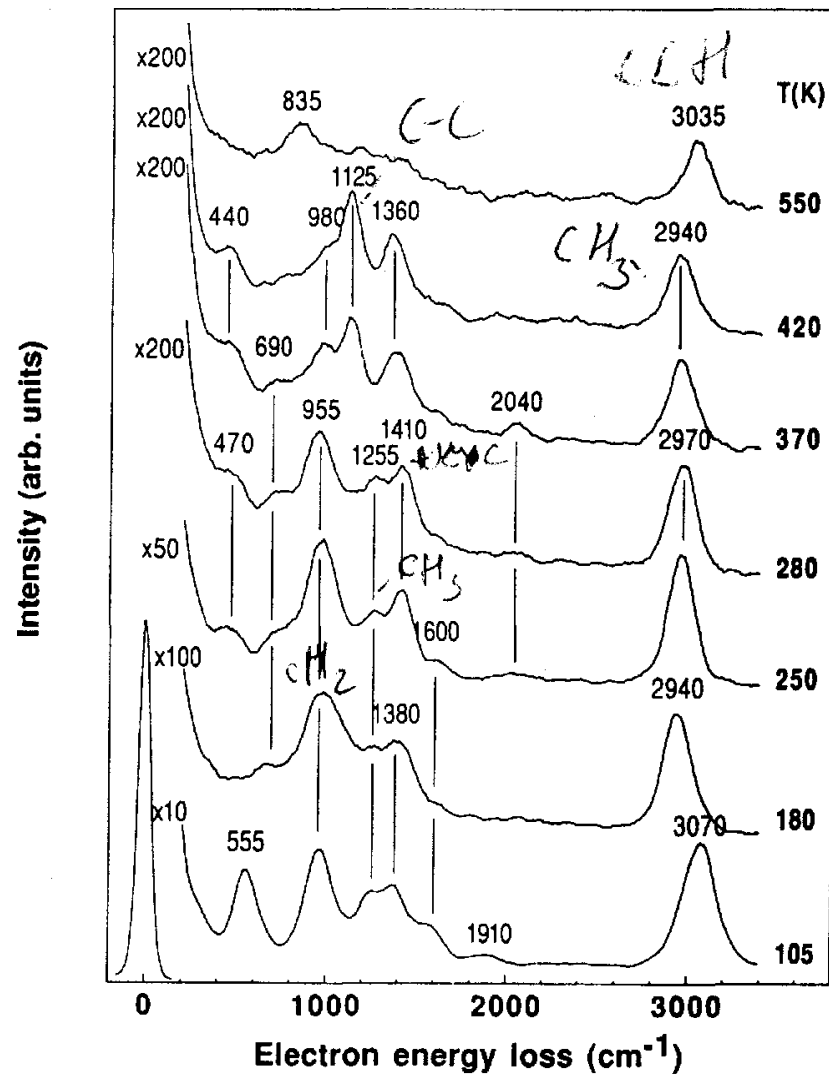

Figure 9. HREELS spectra for a multilayer dose of $\mathrm{C}_{2} \mathrm{H}_{3} \mathrm{I}$ on $\mathrm{Pt}(111)$ at $105 \mathrm{~K}$ (bottom spectrum) and warmed briefly to various temperatures as indicated.

of C-I bonds. This is consistent with the XPS data. According to TPD, monolayer $\mathrm{C}_{2} \mathrm{H}_{3} \mathrm{I}$ has desorbed. Shifts (3000 to 2940 $\mathrm{cm}^{-1}$ and 1565 to $1600 \mathrm{~cm}^{-1}$ ) provide additional evidence for the conversion of molecular $\mathrm{C}_{2} \mathrm{H}_{3} \mathrm{I}$ to $\mathrm{CHCH}_{2}$. The emergence of

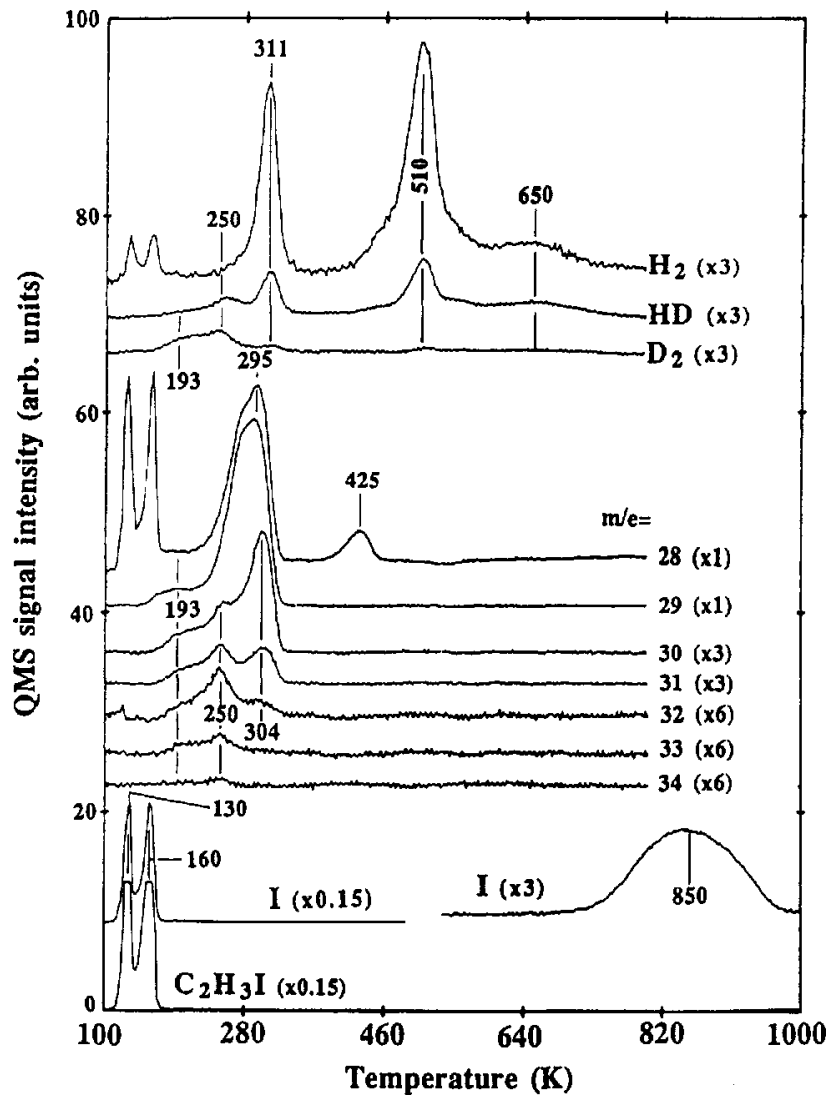

Figure 10. TPD spectra taken after coadsorbing 0.18 ML D and multilayer $\mathrm{C}_{2} \mathrm{H}_{3} \mathrm{I}$ on $\mathrm{Pt}(111)$ at $100 \mathrm{~K}$. Heating rate was $6 \mathrm{~K} / \mathrm{s}$.

a $\mathrm{CH}$ wagging mode at $690 \mathrm{~cm}^{-1}$ also supports the formation of $\mathrm{CHCH}_{2}$ fragments. We believe that $\mathrm{CHCH}_{2}$ fragments dominate at this temperature $(180 \mathrm{~K})$, but there may be small amounts of $\mathrm{CCH}_{3}$ or $\mathrm{C}_{2} \mathrm{H}_{4}$ as well.

New features appear when the surface is heated from 180 to 250 or $280 \mathrm{~K}$, signaling ethylene formation (Table II). First, there is a C-Pt mode at $470 \mathrm{~cm}^{-1}$, and further, the peaks at 1380 and $2940 \mathrm{~cm}^{-1}$ shift to 1410 and $2970 \mathrm{~cm}^{-1}$, respectively. Above 300 $\mathrm{K}$, the losses due to $\mathrm{CCH}_{3}$ (Table III) dominate the spectra, i.e., $440 \mathrm{~cm}^{-1}$ for $\mathrm{Pt}-\mathrm{C}$ stretching, $1125 \mathrm{~cm}^{-1}$ for $\mathrm{C}-\mathrm{C}$ stretching, 1360 $\mathrm{cm}^{-1}$ for $\mathrm{CH}_{3}$ symmetric bending, and $2940 \mathrm{~cm}^{-1}$ for $\mathrm{CH}_{3}$ symmetric and asymmetric stretching. It is noteworthy that there is some evidence for residual $\mathrm{CHCH}_{2}$; the $\mathrm{CH}_{2}$ wagging mode shifts from $955 \mathrm{~cm}^{-1}$ to $980 \mathrm{~cm}^{-1}$ and persists to $420 \mathrm{~K}$, consistent with the proposed high-temperature conversion of vinyl to ethylidyne noted in TPSIMS. Other vinyl losses are presumed unobservable due to low intensity and overlapping. After annealing to $550 \mathrm{~K}$, all the ethylidyne and vinyl features are absent; there are losses at 835 and $3035 \mathrm{~cm}^{-1}$ which correspond to $\mathrm{CH}$ bending and stretching modes ${ }^{18}$ and unresolved intensity throughout the $1000-1600-\mathrm{cm}^{-1}$ region.

3.2. $\mathrm{C}_{2} \mathrm{H}_{3} \mathrm{I} / \mathrm{D} / \mathrm{Pt}(111)$. 3.2.1. TPD. Because of the insight often provided by isotope labeling, we undertook coadsorption studies in which two coverages $(0.18$ and $0.47 \mathrm{ML})$ of preadsorbed $\mathrm{D}$ were covered with slightly more than $1 \mathrm{ML}$ of vinyl iodide at $100 \mathrm{~K}$. In TPD, we observed hydrogenation and H-D exchange products, i.e., D-labeled ethylene and ethane.

Figures 10 and 11 summarize the TPD results for these two cases ( $m / e$ labels on each curve). Compared to vinyl iodide dosed alone (Figures 1 and 2), the presence of $0.18 \mathrm{ML}$ of $\mathrm{D}$ causes the following: (1) It slightly lowers the amount of vinyl iodide decomposed (the I desorption is $90 \%$ of its original value). (2) It leads to facile conversion of vinyl to ethylene (the ethylene desorbs at $295 \mathrm{~K}$, and the dihydrogen desorption at $311 \mathrm{~K}$ marks ethylene-to-ethylidyne conversion). (3) It leads to ethane, which

(18) Demuth, J, E.; Ibach, H. Surf. Sci. 1978, 78, L238. 


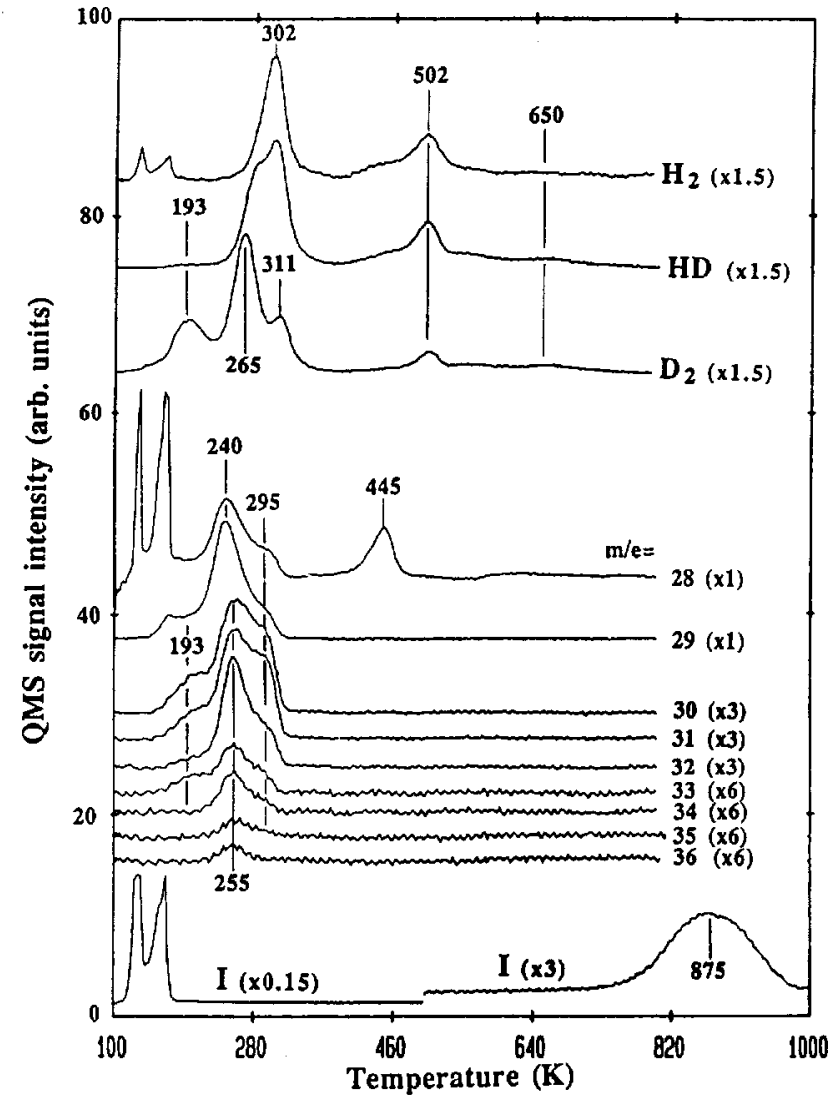

Figure 11. TPD spectra taken after coadsorbing 0.47 ML D and multilayer $\mathrm{C}_{2} \mathrm{H}_{3} \mathrm{I}$ on $\mathrm{Pt}(111)$ at $100 \mathrm{~K}$. Heating rate was $6 \mathrm{~K} / \mathrm{s}$.

forms and desorbs at $250 \mathrm{~K}(30-34 \mathrm{amu})$. (4) It shifts some dihydrogen desorption to $250 \mathrm{~K}$ and, for $\mathrm{D}_{2}$, to $193 \mathrm{~K}$. Note that the $425 \mathrm{~K}$ peak in Figure 10 is caused by background $\mathrm{CO}$. This case is consistent with the hydrogenation of vinyl to ethylene.

Raising the $D$ coverage has a significant impact. Compared to the 0.18-ML case (Figure 10), the presence of $0.47 \mathrm{ML}$ of $\mathrm{D}$ has the following effects (Figure 11): (1) It suppresses vinyl iodide decomposition (the I desorption is $70 \%$ of its former value). (2) It increases the amount of ethane formed, which also has a higher $D$ content (perdeuterated ethane is observed at $36 \mathrm{amu}$, and the 32-amu signal is 5-fold larger). (3) It strongly enhances the amount of dihydrogen desorbed in the $300 \mathrm{~K}$ region. As discussed below, this case is consistent with hydrogenation of vinyl to ethyl at or below $200 \mathrm{~K}$.

Returning to Figure 10 , we note two peaks at $130 \mathrm{~K}$ (multilayer) and $160 \mathrm{~K}$ (monolayer) for molecular vinyl iodide desorption, just as in the absence of D. The area of the $310 \mathrm{~K}$ dihydrogen peak is $\sim 25 \%$ of the total area of the 310,510 , and $650 \mathrm{~K}$ peaks, confirming that, in this case, ethylidyne is formed exclusively from ethylene and not directly from vinyl. For each of the three peak temperatures, the peak areas for the three isotopes have the same ratios ( $23 \% \mathrm{D})$, reflecting the facts that all of the $\mathrm{D}$ is incorporated below $300 \mathrm{~K}$ and isotope effects play a negligible role in the decomposition of ethylidyne and its $\mathrm{C}_{x} \mathrm{H}_{y}$ products. We conclude that, on average, each ethylene contains one D atom.

Dealing with the weak $\mathrm{C}_{2}$ hydrocarbon signals first, we note that $m / e$ values up to 34 , but not higher, are detected. At 250 $\mathrm{K}$ for $m / e=30-34$, there are peaks which are assigned to ethanes containing up to four $\mathrm{D}$ atoms and attributed to self-hydrogenation of ethyl intermediates, based on other work involving ethyl fragments derived from the thermal dissociation of $\mathrm{C}_{2} \mathrm{H}_{5} \mathrm{I}^{2}$ and photodissociation of $\mathrm{C}_{2} \mathrm{H}_{5} \mathrm{Cl}^{19}$ The $\mathrm{C}_{2}$ peak at $304 \mathrm{~K}$ for $\mathrm{m} / \mathrm{e}$ $=30-32$ is attributed, as in other work, ${ }^{20}$ to ethane derived from

(19) Lloyd, K. G.; Roop, B.; Campion, A.; White, J. M. Surf. Sci. 1989, $214,227$.

(20) Zaera, F. J. Phys. Chem. 1990, 94, 5090

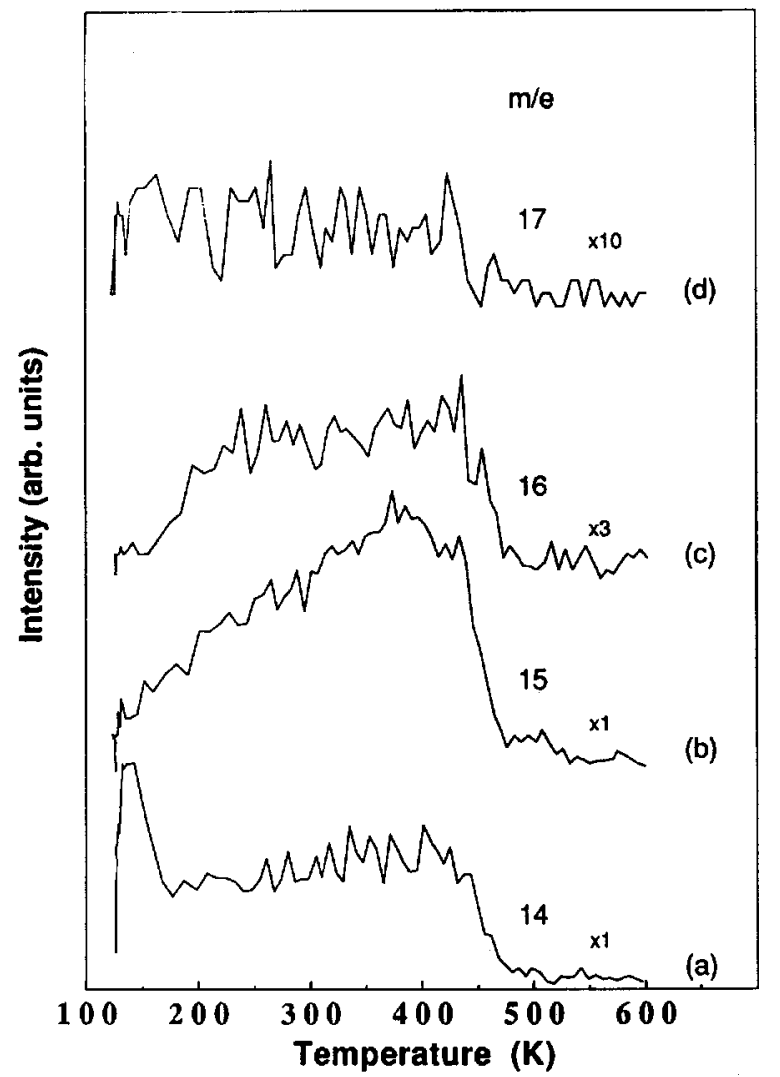

Figure 12. TPSIMS spectra for positive ions after coadsorbing $0.47 \mathrm{ML}$ $\mathrm{D}$ and multilayer $\mathrm{C}_{2} \mathrm{H}_{3} \mathrm{I}$ on $\mathrm{Pt}(111)$ at $120 \mathrm{~K}$. The ion masses are (a) $14\left(\mathrm{CH}_{2}\right),\left(\right.$ b) $15\left(\mathrm{CH}_{3}, \mathrm{CHD}\right)$, (c) $16\left(\mathrm{CH}_{2} \mathrm{D}, \mathrm{CD}_{2}\right)$, and (d) $17(\mathrm{CH}-$ $\left.\mathrm{D}_{2}\right)$. The heating rate was $4.5 \mathrm{~K} / \mathrm{s}$.

the self-hydrogenation of ethylene. The $m / e=32$ signal at 304 $K$ is assigned to $\mathrm{C}_{2} \mathrm{H}_{4} \mathrm{D}_{2}$; its intensity is low. No $\mathrm{C}_{2} \mathrm{H}_{3} \mathrm{D}_{3}$ is detectable. These low intensities reflect the relatively low concentration of $D$ and, in this temperature region, the rapidly increasing concentration of $\mathbf{H}$ as ethylene decomposes to ethylidyne. The small peak at $193 \mathrm{~K}$ for $m / e=30-33$ is coincident with $D_{2}$ desorption and is attributed to the facile, but transient, deuteration of vinyl (i.e., $3 \mathrm{D}(\mathrm{a})+\mathrm{CHCH}_{2}(\mathrm{a}) \rightarrow \mathrm{C}_{2} \mathrm{H}_{3} \mathrm{D}_{3}$ ). At this temperature, we suppose that isotope exchange is not competitive. If it were, we would observe even more incorporation of $D$.

Turning to the dominant signals (note the scale factors) in the $\mathrm{C}_{2}$ region, $m / e=28$ and 29 track each other and show an intense peak at $295 \mathrm{~K}$ with a shoulder on the low-temperature side. Comparing fragmentation patterns, we conclude that the $m / e=$ 28 signal is mainly due to the cracking of $\mathrm{C}_{2} \mathrm{H}_{3} \mathrm{D}(m / e=29)$, a conclusion entirely consistent with the above dihydrogen analysis. While these peaks certainly contain contributions from the fragmentation of the ethane formed at 250 and $304 \mathrm{~K}$, these contributions are negligibly small.

For the most part, a similar analysis is obtained for the higher $D$ coverage. Among the differences, there is isotope labeling that requires exchange. For example, the peaks at $255 \mathrm{~K}$ for $m / e=$ $30-36$ are assigned to ethane with up to six D atoms ( $36 \mathrm{amu}$ ). Hydrogenation without the exchange of $\mathrm{CHCH}_{2}$ would give no more than three $D$ atoms so that, not surprisingly, ${ }^{21-23}$ isotope exchange is competitive here. The signal for $m / e=35$ is exclusively $\mathrm{C}_{2} \mathrm{HD}_{5}$, again indicating isotope exchange. The ethylene self-hydrogenation peaks ( $295 \mathrm{~K}$ ) contain up to five $\mathrm{D}$ atoms $\left(C_{2} \mathrm{HD}_{5}\right.$ is seen), whereas no more than two $\mathrm{D}$ atoms were found for $0.18 \mathrm{ML} \mathrm{D}$. There are additional peaks at $240 \mathrm{~K}$ for $\mathrm{m} / \mathrm{e}$ $=28$ and 29 ; these are attributed to $\mathrm{C}_{2} \mathrm{H}_{3} \mathrm{D}(m / e=29)$ and its fragment at $m / e=28$, a product of direct deuteration of $\mathrm{C}_{2} \mathrm{H}_{3}$.

(21) Zaera, F. J. Phys. Chem. 1990, 94, 8350.

(22) Creighton, J. R.; Ogle, K. M.; White, J. M. Surf. Sci. 1984, 138, 137.

(23) Liu, Z.-M.; Zhou, X.-L.; White, J. M. Appl. Surf. Sci. 1991, 52, 249. 
For the hydrogen isotopes, the spectra are, with one exception, very similar to those observed by Zaera, ${ }^{21}$ who studied $\mathrm{CD}_{3} \mathrm{CH}_{2} \mathrm{I} / \mathrm{Pt}(111)$. For example, the peak at $265 \mathrm{~K}$ for $\mathrm{D}_{2}$ and the shoulder near $265 \mathrm{~K}$ for $\mathrm{H}_{2}$ and $\mathrm{HD}$ are due to dehydrogenation of ethyl to ethylene. Lower intensity peaks, attributed to the same origin, $2,19,24$ appear at $250 \mathrm{~K}$ in Figure 10. Thus, vinyl hydrogenation to ethyl is facile below $250 \mathrm{~K}$ in the presence of excess surface atomic hydrogen. The higher temperature peaks are due to the conversion of ethylene to ethylidyne and the decomposition of ethylidyne. In this case, we calculated, as described above, that the $H / D$ ratio in ethylidyne is about $1: 1$. The 193 $K$ peak for $D_{2}$ is an exception and is attributed to the low-temperature recombinative desorption of atomic $\mathrm{D}$ under conditions of surface crowding. We conclude that surface ethyl is the dominant intermediate for $\mathrm{C}_{2} \mathrm{H}_{3} \mathrm{I} / 0.47 \mathrm{ML} \mathrm{D} / \mathrm{Pt}(111)$ and that it facilitates isotope exchange.

3.2.2. TPSIMS. Figure 12 shows TPSIMS spectra of $\mathrm{m} / \mathrm{e}$ $=14,15,16$, and 17 (attributable to $\mathrm{CH}_{2} ; \mathrm{CH}_{3}$ and $\mathrm{CHD} ; \mathrm{CH}_{2} \mathrm{D}$ and $\mathrm{CD}_{2}$; and $\mathrm{CHD}_{2}$, respectively) following coadsorption of $\sim 0.44 \mathrm{ML} \mathrm{C}_{2} \mathrm{H}_{3} \mathrm{I}$ and $0.47 \mathrm{ML}$ D. Only a small low-temperature signal for $m / e=18$ was observed; this signal and the low-temperature portion of the $m / e=17$ signal correlate with the desorption of small amounts of background water. There was no evidence for $\mathrm{CD}_{3}$ formation. In curve a, the peak around $140 \mathrm{~K}$ for $\mathrm{CH}_{2}$ is from parent $\mathrm{C}_{2} \mathrm{H}_{3} \mathrm{I}$. Curve $b$ is similar to curve $a$ in Figure 7, but the plateau between 200 and $300 \mathrm{~K}$ is not obvious here, for two possible reasons: (1) The formation and decomposition of deuterated ethylene is dominant. (2) The signal-to-noise ratio is not as good. Curve c rises above $150 \mathrm{~K}$, consistent with the TPD of deuterated ethylene. Isotope exchange in ethylidyne formation confirms this notion.

\section{Discussion}

From the above results and the comparisons made, the following picture emerges, which sheds some light on the mechanism for the conversion of chemisorbed ethylene to ethylidyne on $\mathrm{Pt}(111)$. Partial decomposition, $\mathrm{C}-\mathrm{I}$ bond cleavage, occurs during adsorption of monolayer $\mathrm{C}_{2} \mathrm{H}_{3} \mathrm{I}$ on $\mathrm{Pt}(111)$ at $100 \mathrm{~K}$. During thermal desorption, additional $\mathrm{C}-\mathrm{I}$ bond cleavage occurs up to the desorption temperature of the chemisorbed parent $(160 \mathrm{~K})$. Depending on the coverage of atomic hydrogen, one of three surface reaction channels operates:

$$
\begin{gathered}
\text { (a) }-\mathrm{CH}=\mathrm{CH}_{2} \rightarrow-\mathrm{C}-\mathrm{CH}_{3} \\
\text { (b) }-\mathrm{CH}=\mathrm{CH}_{2}+\mathrm{H} \rightarrow-\mathrm{CH}_{2}-\mathrm{H}_{2} \mathrm{C}- \\
\text { (c) }-\mathrm{CH}=\mathrm{CH}_{2}+2 \mathrm{H} \rightarrow-\mathrm{CH}_{2} \mathrm{CH}_{3}
\end{gathered}
$$

The relative importance depends on the surface hydrogen coverages: channel a dominates for hydrogen-deficient surfaces, $b$ dominates for intermediate coverages of atomic hydrogen, and c dominates for high coverages of preadsorbed hydrogen.

The importance of channel a is evidenced by (1) the rise at 120 $\mathrm{K}$ of the $\mathrm{CH}_{3}^{+}$signal in TPSIMS, (2) the shoulder at $1125 \mathrm{~cm}^{-1}$ in HREELS spectra of low $\mathrm{C}_{2} \mathrm{H}_{3} \mathrm{I}$ coverages, (3) the presence of strong ethylidyne vibrational modes above $300 \mathrm{~K}$, and (4) the strong $520 \mathrm{~K}$, but the absence of $300 \mathrm{~K}, \mathrm{H}_{2}$ TPD.

Channel $\mathrm{b}$ is evidenced by (1) strong hydrogen desorption at 300 and $520 \mathrm{~K}$, just as found for the conversion of ethylene to ethylidyne, (2) negligible ethylene desorption for low doses of vinyl iodide, (3) steadily increasing amounts of ethylene desorption above a threshold vinyl iodide coverage, and (4) significant ethylene desorption, dominated by $\mathrm{C}_{2} \mathrm{H}_{3} \mathrm{D}$, when $20 \%$ of a monolayer of $D$ is preadsorbed.

Channel $\mathrm{c}$ is evidenced by (1) the desorption of a significant amount of ethane at temperatures known to hydrogenate ethyl fragments and (2) the desorption of ethylene at temperatures where ethyl is known to dehydrogenate.

If ethylene converts to ethylidyne via vinyl, one might question why no vinyl intermediates have been detected when ethylene is dosed on $\mathrm{Pt}(111)$. This is readily explained because the $\mathrm{C}-\mathrm{H}$ bond

(24) Zaera, F. J. Am. Chem. Soc. 1989, 111, 8744. in adsorbed ethylene breaks $(>250 \mathrm{~K})$ at temperatures where vinyl rearrangement to ethylidyne is facile $(<200 \mathrm{~K})$. Unless special circumstances exist, vinyl from ethylene is stabilized; it will never accumulate. On the basis of TPSIMS, XPS, and HREELS, we have found in this study that atomic iodine stabilizes some vinyl, to as high as $450 \mathrm{~K}$. There is some evidence that preadsorbed atomic oxygen may also stabilize some vinyl, because there is an extra $\mathrm{CH}_{3}^{+}$peak at $450 \mathrm{~K}^{.11}$

It is interesting to examine the evidence for isotope exchange. In the presence of preadsorbed D, parent vinyl iodide TPD is unlabeled. Thus, exchange does not occur prior to $\mathrm{C}-\mathrm{I}$ bond breaking and desorption of the parent. Exchange into the vinyl species occurs, but at low temperatures and high atomic hydrogen concentrations, hydrogenation to ethyl dominates and exchange in the latter is facile.

The absence of exchange into the parent suggests that the adsorption geometry of vinyl iodide is similar to that of methyl halides on Pt(111), ${ }^{25}$ i.e., bonding through the iodine with the vinyl part pointed into the vacuum. This geometry is consistent with the HREELS data since the intense $C=C$ stretch suggests that the axis through the two carbon atoms should not be parallel to the surface.

When $\mathrm{C}-\mathrm{I}$ bonds break, the vinyl bonding geometry is not clear. Henderson et al..$^{26}$ proposed $\eta^{2}$-(C,C) $\mathrm{CHCH}_{2}$ as an intermediate for ethylene decomposition on $\mathrm{Ru}(001)$. Carter and $\mathrm{Koel}^{4}$ propose, on the basis of theoretical considerations, a similar fully rehybridized $\mathrm{CHCH}_{2}$ species as an important ethylene decomposition intermediate. On the basis of these previous experimental and theoretical studies, we cannot rule out the possibility of $\eta^{2}-(\mathrm{C}, \mathrm{C})$ $\mathrm{CHCH}_{2}$. However, the appearance of the $\mathrm{C}=\mathrm{C}$ stretching mode at $1600 \mathrm{~cm}^{-1}$ up to $250 \mathrm{~K}$ suggests that at least part of the surface vinyl retains its $\mathrm{C}=\mathrm{C}$ double bond. While the $\eta^{2}$ structure may make it easier to account for deuterium exchange, we note that isotope exchange does occur in ethylidyne adsorbed on $\operatorname{Pt}(111)^{22}$ and that, in the presence of ethylidyne, ethylene can be hydrogenated to ethane. ${ }^{27}$

According to theoretical calculations, ${ }^{4}$ the mechanism by which ethylene undergoes $\alpha-\mathrm{H}$ cleavage to form vinyl (the reverse of channel b) and further isomerizes to form ethylidyne cannot be ruled out on the basis of reaction energetics alone. The estimated barrier for $\alpha-\mathrm{H}$ cleavage is fairly large, an expectation confirmed by the isotope effects noted in Figures 4 and 7 . This barrier may account for why ethylidyne from ethylene sets in at $310 \mathrm{~K}$, whereas ethylidyne from vinyl occurs below $200 \mathrm{~K}$.

\section{Conclusions}

Vinyl iodide adsorbs on $\mathrm{Pt}(111)$ at $100 \mathrm{~K}$ both molecularly and dissociatively. At high coverages, both the multilayer and monolayer of vinyl iodide desorb at 130 and $160 \mathrm{~K}$, respectively. During heating, additional $\mathrm{C}-\mathrm{I}$ bond cleavage occurs below the monolayer desorption temperature and, overall, $70 \%$ of the vinyl iodide in the first layer dissociates. In the absence of coadsorbed atomic hydrogen, there are two competitive reaction channels for vinyl species:

$$
\begin{gathered}
\text { (a) }-\mathrm{CH}=\mathrm{CH}_{2} \rightarrow-\mathrm{CCH}_{3} \\
\text { (b) }-\mathrm{CH}=\mathrm{CH}_{2}+\mathrm{H} \rightarrow-\mathrm{CH}_{2} \mathrm{H}_{2} \mathrm{C}-
\end{gathered}
$$

Vinyl conversion to ethylidyne, reaction a, starts at $120 \mathrm{~K}$, but in the presence of large amounts of $I$, there is evidence that some vinyl species are stable up to $450 \mathrm{~K}$. Reaction $\mathrm{b}$ is enhanced when surface hydrogen is available, as it is when $D$ is preadsorbed or when intermediate coverages of the parent allow for low-temperature $\mathrm{C}-\mathrm{H}$ cleavage. The desorption of the ethylene from $\mathrm{C}_{2} \mathrm{H}_{3} \mathrm{I}$ is reaction-limited and occurs at a lower temperature than

(25) Henderson, M. A.; Mitchell, G. E.; White, J. M. Surf. Sci. 1987, 184, L325.

(26) Henderson, M. A.; Mitchell, G. E.; White, J. M. Surf. Sci. 1988, 203, 278.

(27) Godbey, D.; Zaera, F.; Yeates, R.; Somorjai, G. A. Surf. Sci. 1986, 167,150 .

(28) Torkington, P.; Thompson, H. W. J. Chem. Soc. 1944, Part I, 303. 
for ethylene chemisorbed alone on $\operatorname{Pt}(111)$.

The results suggest that the first $\mathrm{C}-\mathrm{H}$ bond cleavage is the rate-determining step for ethylidyne formation from ethylene on $\mathrm{Pt}(111)$ and that vinyl is a facile intermediate in the conversion of ethylene to ethylidyne.

For high coverages of preadsorbed $D$, hydrogenation of vinyl to ethyl occurs and leads to TPD product distributions that are consistent with those measured when starting with ethyl iodide. ${ }^{2}$
Moreover, isotope exchange is facile, leading to some perdeuterioethane desorption.

Acknowledgment. This work was supported in part by the U.S. Department of Energy, Office of Basic Energy Sciences, and by the Exxon Education Foundation.

Registry No. $\mathrm{H}_{2} \mathrm{C}=\mathrm{CHI}$, 593-66-8; $\mathrm{Pt}, 7440-06-4 ; \mathrm{H}_{2} \mathrm{C}=\mathrm{CH}_{2}, 74$. 85-1; ethylidyne, 67624-57-1; vinyl, 2669-89-8. 